\title{
Emergency oral contraceptive use among undergraduate female students of mizan-tepi University, mizan campus south nations nationalities and peoples regional state south west, Ethiopia 2016
}

\begin{abstract}
Background: Unintended pregnancies are major public health concern in developing countries including Ethiopia. Female university students face unintended pregnancies because most of them are sexually active and exposed to unprotected sporadic premarital sexual intercourse. Emergency Contraception is a drug or a device that prevents unintended pregnancy and its consequences. Emergency Oral Contraceptives are being increasingly used by unmarried young women to prevent unintended pregnancies following unprotected sexual intercourse. However, little is known about Emergency Oral Contraception (EOC) use among female students at higher education in Ethiopia.
\end{abstract}

Objectives: The main objective of this study was to assess the prevalence of Emergency Oral Contraceptive (EOC) use among Mizan-Tepi University, Mizan campus undergraduate regular female student 2016.

Methods: Institution based cross-sectional study was conducted on 324 undergraduate female students of Mizan-Tepi University, Mizan campus. Data were collected from March 1-21, 2017. Study participants were selected using stratified sampling technique. Selfadministered pretested structured and semi-structured questionnaire was used to collect the data. Descriptive analysis was applied to describe the Emergency oral contraceptive use.

Results: Regarding utilization of Emergency oral Contraceptives, among those who reported to have sexual intercourse, $78(82.97 \%)$ reported use of Emergency oral Contraceptives and it was $76(95 \%)$ among those who had unprotected sex.

Conclusion and recommendation: There is very high level of Emergency oral Contraceptives use among sexually active female undergraduate students who had unprotected sexual intercourse. Given that Emergency oral Contraceptives use among female students is very high among those who reported sexual intercourse we recommend that zonal health department, town heath office, Mizan-Tepi University health Science College and Mizan-Tepi University HIV coordination should give reproductive health education, risk of unprotected sex.

Keywords: emergency contraceptives, oral, HIV, EOC
Volume 4 Issue I - 2018

\author{
Yayehyirad Yemaneh,' Alemayehu Sayih, ${ }^{2}$ \\ Wondwessen Niguse, ${ }^{2}$ Meaza Lema, ${ }^{2}$ \\ Ashenafi Tsegaye ${ }^{2}$ \\ 'Department of Midwifery, Mizan-Tepi University, Ethiopia \\ ${ }^{2}$ Department of Nursing, Mizan-Tepi University, Ethiopia
}

Correspondence: Yayehyirad Yemaneh, Lecturer, Department of Midwifery College of Health Sciences, Mizan-Tepi University, Ethiopia, Tel +25 1912 087869, +25 1932 520242, Email buchiatuog@gmail.com

Received: November 10, 2017 | Published: February 27, 2018

\section{Introduction}

Emergency Contraception (EC) is a birth control that is used after unprotected sex, contraceptive failure and rape. Terms used to describe EC include post-coital contraception and the morning after pill. Emergency contraceptives are intended to provide second chance to prevent pregnancy for women who have been exposed to unprotected sexual intercourse and who don't wish to become pregnant. ${ }^{1,2}$

Emergency Oral Contraceptives (EOC) is a progestin only or pills containing a combination of a progestin and an estrogen. Effectiveness of EOC the progestin only regimen reduces the risk of pregnancy after a single act of sexual intercourse by about $60-93 \%$ and the combined regimen by about $56-89 \%$. EOC reduces the risk of pregnancy by up to $95 \%$. With respect to mechanism of action, EC works by preventing fertilization, implantation, tubal transportation of sperm and ovum. ${ }^{1,2}$
Although hormonal contraceptives were developed since mid1920 s in the world ${ }^{3}$ Emergency Contraceptives (EC) were first introduced to the Ethiopian public sector in 1997G.C. ${ }^{4}$

The primary use of Emergency Oral Contraceptive is in reducing the need for abortions and the negative maternal health consequences associated unintended pregnancy. ${ }^{5}$ Emergency oral contraceptive is found to be effective if used as soon as possible after unprotected sexual intercourse, especially within 72 hours of unprotected sexual intercourse. ${ }^{6}$ Lack of health services for young people and limited access to targeted reproductive health care contributes to and exacerbates many of their reproductive health problems. Over a quarter of all pregnant youth and adolescents report that their pregnancies are unplanned, reflecting this populations unmet need for family planning and reproductive health services. ${ }^{7,8}$ 
Unavailability of family planning and reproductive health services has even more serious consequences for countries like Ethiopia where over $65 \%$ of its population is under 25 years of age with profound reproductive health needs. As a result, Ethiopian youth face many sexual and reproductive health problems including sexual coercion, unintended pregnancies, abortion, sexually transmitted Infections (STIs) including HIV/AIDS. ${ }^{9}$

In response to this growing challenge the government of Ethiopia has introduced several reproductive health intervention targeting adolescents and youth. One of the interventions to reduce unintendedpregnancy and unsafe abortion outlined in the national adolescent and youth strategy is availing Emergency Contraceptive (EC). However, information about EOC use is limited. ${ }^{7}$

Globally, there are about 210 Million pregnancies each year, some 80 million of these are unintended and one in ten of these pregnancies end in an unsafe abortion. An estimated 529,000 girls and women die from pregnancy-related causes each year worldwide, of which $13 \%$ are due to unsafe abortion. It is estimated that two in five unsafe abortions occur among women under age 25 and about one in seven women who have unsafe abortions are under $20 .^{10,11}$

In Africa, among the annual number of induced abortions (6.4million), only $3 \%$ are performed under safe conditions. Eastern African countries contributed nearly $39.1 \%$ (2.5million) of all induced abortions occurred in Africa in 2008, a higher proportion than in any other regions of the continent. ${ }^{12}$

Based on the World Health Organization (WHO) estimate the level of Maternal Mortality Ratio (MMR) in Ethiopia is among the highest in the world with 412 maternal deaths per 100,000 live births. ${ }^{13}$ One of the interventions to prevent maternal deaths particularly among young people is through preventing unintended pregnancies and abortion through use of Emergency Oral Contraceptive. ${ }^{14}$

Most of the pregnancies among students in Ethiopian university are unintended. Unintended pregnancy either ends with unsafe abortion or early child bearing; it has a negative impact on educational progress, future careers and even social interaction of female students by forcing them to drop out of school. On the other hand, this segment of population is tomorrow's generation in pipeline to take over the responsibilities of socioeconomic development of the country. Thus, they should be protected from unintended pregnancy that could have been considerably prevented by emergency contraception. ${ }^{15-19}$ Despite high rate of unintended pregnancies among university students there is low uptake of contraceptive methods including emergency contraceptives. ${ }^{20-22}$ So that this study focused on its magnitude and the various factors responsible for Emergency Oral Contraceptive use among Mizan Tepi University Mizan campus students.

\section{Methodology}

\section{Study esign}

Institution based descriptive cross-sectional Study design was employed.

\section{Source population}

All undergraduate regular female students of Mizan-Tepi University, Mizan campus.

\section{Study population}

Randomly Selected undergraduate regular female students of Mizan-Tepi University found during data collection period, Mizan campus, 2016/17

\section{Inclusion criteria}

All undergraduate regular female students of Mizan-Tepi University, Mizan campus, 2016/17

\section{Exclusion criteria}

Participants who cannot communicate by any means during data collection time.

\section{Sample size determination and sampling procedure}

The sample size was calculated using a single population proportion formula based on the prevalence of emergency contraceptive use assumed to be $44 \%$ which is taken from research which is done in Wachamo University. The confidence interval of $95 \%$ and margin error of $5 \%$ to get the possible sample size. $n=378$. Since the source population is less than 10,000 we have used the following correction formula, $\mathrm{nf}=\mathrm{n} / 1+(\mathrm{n} / \mathrm{N})$, then finally Assuming $10 \%$ (31.1) nonresponse rate gave us 342 and to obtain a representative sample, stratified sampling technique was applied to select study participants from the source population. First the students were divided in to two practical strata, which is health science college and other colleges. The total sample size was allocated to each stratum, which was to college of health science and other colleges based on Proportional to Size (PPS) of female students in each college. Again from college, we merged to each department within the college based on probability proportional to number of students in each department. Finally study units were selected from each department using Simple Random Sampling (SRS) technique using lottery method.

\section{Data collection method and data quality management}

Structured and semi-structured questionnaire was prepared in English after reviewing literature of similar survey that have been carried out previously, including Ethiopia Demographic Health Survey (EDHS). Data was collected using self-administered questionnaire.

To maintain the quality of data, structured and semi-structured questionnaire was prepared in English language and then translated to Amharic language. To check the clarity, consistency, skipping pattern and order of questions, questionnaire was pre-tested on $5 \%$ of the calculated sample size in Tepi campus computer science students. Then the questionnaire was modified based on information obtained from pre-test results. Data collection period will be in the morning at the weekend after giving orientation. Offensive words were removed and the questionnaire was self-administered since it is sensitive and private issue. Then the questionnaire was checked for completeness by principal investigators on daily basis.

\section{Data analysis}

The collected data was cleared and checked for completeness. Data was analyzed manually using digital calculator and using computer. Additionally, the result of the study was presented using tables, charts and texts. 


\section{Ethical consideration}

A formal letter was obtained from Mizan-Tepi University, College of health science Department of Nursing. The purpose of study was explained to the study subject at the time of data collection and verbal consent was taken from participants to conform whether they are willing to participate. Those who are not willing to participate were given the right to do so. Confidentiality of respondents was ensured throughout the research process.

\section{Results}

\section{Socio demographic characteristics}

A total of 329 female students completed the questioner making a response rate of 329 (96.54\%). Concerning the age, $214(65.54 \%)$ of respondents are between 20-24age group. More than half (53.19\%) of the respondents were followers of the Orthodox Christianity followed Protestant and Muslim which accounted for 75 (22.79\%) and 55 $(16.71 \%)$ respectively. Regarding the marital status of the respondents $318(96.65 \%)$ was single. With respect to current place of residence about $315(95.74 \%)$ of the participants reported that they live inside the university dormitory (Figure 1) (Figure 2) (Table 1).

Table I Socio-demographic characteristics of undergraduate regular female students of Mizan-Tepi University, South Nations Nationalities and Peoples Regional State, south west Ethiopia, June, 2017(n=329)

\begin{tabular}{|c|c|c|}
\hline Variables & Number & Percent \\
\hline \multicolumn{3}{|l|}{ Field of study } \\
\hline Other college & 250 & $75.98 \%$ \\
\hline Health college & 79 & $24.04 \%$ \\
\hline \multicolumn{3}{|l|}{ Religion } \\
\hline Orthodox & 175 & $53.19 \%$ \\
\hline Protestant & 75 & $22.79 \%$ \\
\hline Muslim & 55 & $16.71 \%$ \\
\hline Catholic & 20 & $6.07 \%$ \\
\hline Others & 4 & $1.20 \%$ \\
\hline \multicolumn{3}{|l|}{ Ethnicity } \\
\hline Amhara & 115 & $34.95 \%$ \\
\hline Oromo & 110 & $33.95 \%$ \\
\hline Wolyita & 37 & $11.24 \%$ \\
\hline Gurage & 25 & $7.59 \%$ \\
\hline Tigray & 22 & $6.68 \%$ \\
\hline Others & 20 & $6.07 \%$ \\
\hline \multicolumn{3}{|l|}{ Marital status } \\
\hline Single & 318 & $96.65 \%$ \\
\hline Married & II & $3.34 \%$ \\
\hline \multicolumn{3}{|c|}{ Current residence } \\
\hline In campus & 315 & $95.74 \%$ \\
\hline Out of campus with family & 9 & $2.73 \%$ \\
\hline Out campus alone & 5 & $1.51 \%$ \\
\hline
\end{tabular}

Age of Respondets

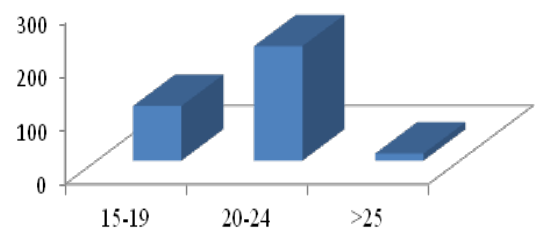

Age of Respondets

Figure I Showing Age of the Respondents of the undergraduate regular female students of Mizan-Tepi University, South Nations Nationalities and Peoples Regional State south west Ethiopia, June, 2017(n=329).

Year of Study

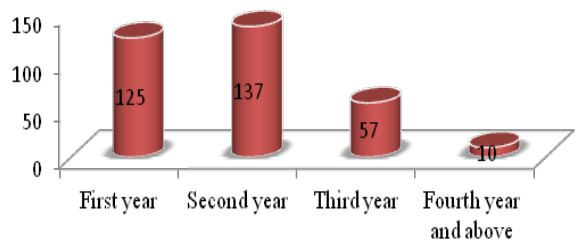

Figure 2 Showing Year of Study of the undergraduate regular female students of Mizan-Tepi University, South Nations Nationalities and Peoples Regional State south west Ethiopia, June, 2017( $n=329)$.

\section{Sexual and reproductive characteristics}

Among the total female students who participated in this study, $94(28.57 \%)$ reported having had sexual intercourse. Of these, $73(77.65 \%)$ had their first sexual intercourse before they were 19 years of age. Among sexually active respondents $80(85.1 \%)$ had unprotected sexual intercourse and $17(18.08 \%)$ had sex with two or more partners. Ninety-four $(28.57 \%)$ of those who had sexual intercourse, $(11.70 \%)$ of all study participants were pregnant at least once and most $(81.81 \%)$ of the pregnancies were unintended. Lack of knowledge about contraception $4(44.44 \%)$, contraceptive failure $2(22.22 \%)$ and forget to take contraceptive $3(33.33 \%)$ were their reported main reasons for unintended pregnancies. The majority $(72.72 \%)$ of pregnancies were terminated by induced abortion (Figure 3) (Table 2).

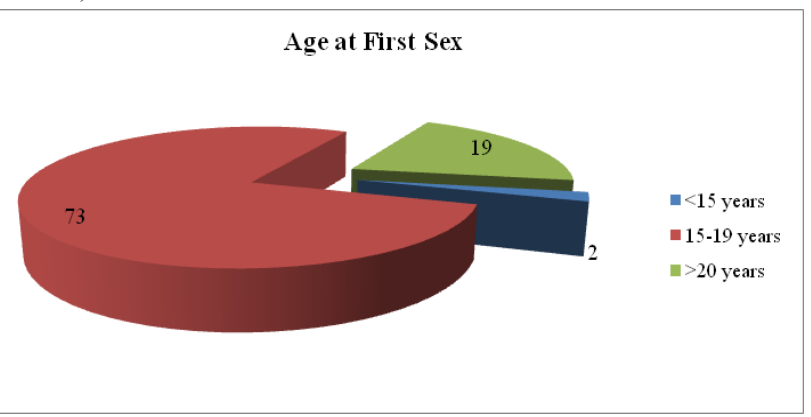

Figure 3 Showing Age at First Sex of undergraduate regular female students of Mizan-Tepi University, South Nations Nationalities and Peoples Regional State ,south west Ethiopia, June, 2017(n=329). 
Table 2 Sexual and reproductive history of undergraduate regular female students of Mizan-Tepi University, South Nations Nationalities and Peoples Regional State, south west Ethiopia, June, 2017( $n=329)$

\begin{tabular}{ccc}
\hline Variables & Number & Percent \\
\hline Ever had sex since in the campus $(\mathrm{n}=329)$ & \\
No & 235 & $71.42 \%$ \\
Yes & 94 & $28.57 \%$ \\
Unprotected sex $(n=94)$ & \\
Yes & 80 & $85.10 \%$ \\
No & 14 & $14.89 \%$ \\
Multiple sexual partner $(n=94)$ & \\
One & 77 & $81.91 \%$ \\
Two or more & 14 & $18.08 \%$
\end{tabular}

Frequency of sexual intercourse per week $(n=94)$

\section{One time \\ Two times}

Three or more times

Ever had STIs $(n=94)$

No

History of pregnancy $(n=94)$

No

83

Yes

$$
\text { II }
$$

$88.29 \%$

I I.70\%

Unintended pregnancy $(n=\mid I)$

Yes

9

No

2

$18.18 \%$

Experience of induced abortion $(n=I I)$

$\begin{array}{lll}\text { Yes } & 8 & 72.72 \% \\ \text { No } & 3 & 27.27 \%\end{array}$

Reasons for induced abortion $(n=8)$

Fear of discontinuing school

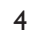

Fear of parents and family

4

2

$50 \%$

$25 \%$

Economic problem

I

$12.50 \%$

\section{Use of emergency oral contraception}

Regarding utilization of Emergency Oral Contraceptives, among those who reported to have sexual intercourse, $78(82.97 \%)$ reported use of Emergency Oral Contraceptives (EOC)and it was 76(95\%) among those who had unprotected sex. From those respondents who were reported use of Emergency Oral Contraceptives (EOC), those from other college and health college are 55(55.35\%) and 26(27.62\%) respectively.

Respondents were asked who told them to use Emergency Oral Contraceptives (EOC). The majority of them $(35.89 \%)$ mentioned their female friends followed by health professionals $(29.48 \%)$ and boyfriends (25.64\%). Unprotected sexual intercourse (73.07\%), forgetting to take contraception $(14.10 \%)$, failure of contraceptive $(7.69 \%)$ and others $(5.12 \%)$ were the main reasons to use Emergency Oral Contraceptives (Figures 4-6).

\section{Frequency of Emergency Oral Contraceptive Use}

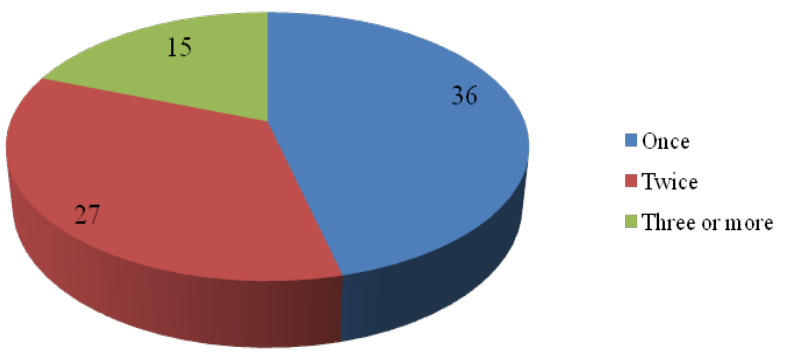

Figure 4 Showing Frequency of Emergency Oral Contraceptives use of undergraduate regular female students of Mizan-Tepi University, South Nations Nationalities and Peoples Regional State, south west Ethiopia, June, $2017(n=78)$.

Source of Information To Use

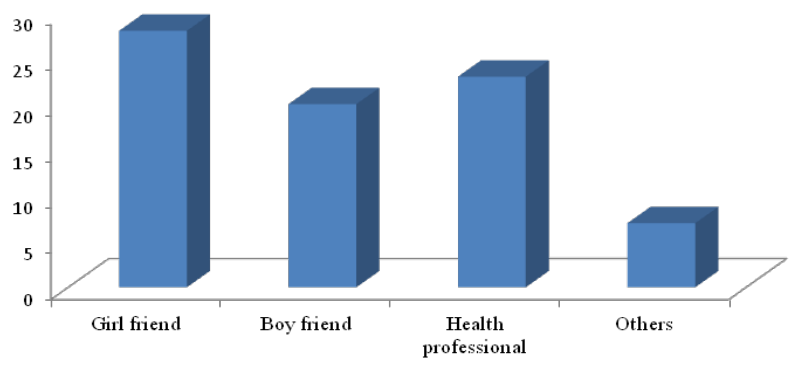

Figure 5 Showing Source of Information for Emergency Oral Contraceptive Use of undergraduate regular female students of Mizan-Tepi University, of the undergraduate regular female students of Mizan-Tepi University, South Nations Nationalities and Peoples Regional State, south west Ethiopia, June, $2017(n=78)$.

Reasons for use of Emergency Oral Contraceptives

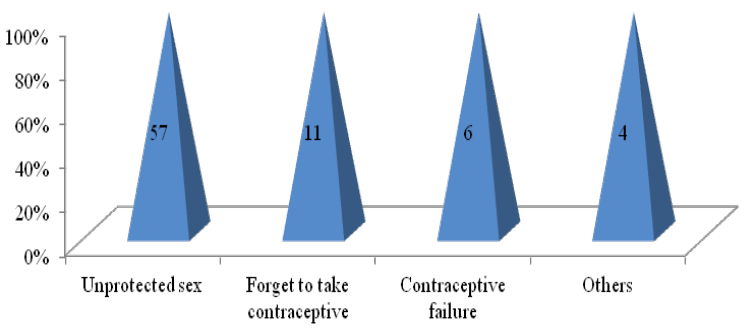

Figure 6 Showing Reason to Use Emergency Oral Contraceptive of undergraduate regular female students of Mizan-Tepi University, of the undergraduate regular female students of Mizan-Tepi University, South Nations Nationalities and Peoples Regional State, south west Ethiopia, June, $2017(n=78)$ 


\section{Discussion}

This study found that $78(82.97 \%)$ of study participants practiced Emergency Oral Contraceptive since in the campus, which is higher compared to what have been reported by studies among university students in South Africa and Cameroon $(21.2 \%, 7.4 \%)$ respectively. ${ }^{23,24}$ The possible explanation for a higher Emergency Oral Contraceptive practice observed in this study might be related to difference in sample size between the two studies and level of awareness as the time of the study goes on might also be another possible explanation. Among the respondents who reported having ever had unprotected sexual intercourse almost all of them reported using Emergency Oral Contraceptive (95\%). This proportion is very high compared to Emergency Oral Contraceptive use reported by other studies ${ }^{20,25,26}$ The possible reasons for a high Emergency Oral Contraceptive practice observed in the studies might be partially explained by the fact that a higher proportion of sexually active students among the participants in the studies. ${ }^{27}$

In this study about $94(28.57 \%)$ of the students reported that they are sexually active. This result is higher than similar study conducted in Adama and Addis Ababa University among female undergraduate students. ${ }^{28,29}$ The difference could be due to cultural variation and economic status among study participants.

\section{Limitation of the study}

The study employed a cross-sectional study design and can't establish cause and effect associations. This study cannot guarantee that students provided honest answers to the questions, since the survey involved a sensitive matter. Therefore, it is important to remember that the reliability of results of this study is dependent upon the accuracy of the responses.

A prospective study design with follow up could have been more robust method to identify associated factors for Emergency Oral Contraceptive use this couldn't be used because of the limitation in resource and time.

\section{Conclusion}

Emergency Oral Contraceptive use among undergraduate female university students who had reported unprotected sexual intercourse is very high. There is very high rate of unintended pregnancies and induced abortion among sexually active female university students.

\section{Recommendation}

Despite the high use of Emergency Oral Contraceptive among the study participants the fact that relatively high proportions of students are sexually active and do not use barrier methods to prevent STI/HIV is a serious concern.

Use of Emergency Oral Contraceptive among almost all female university students who had unprotected sexual intercourse may indicate the lack of information and access to regular contraceptive methods which are more efficacious.

Given that Emergency Oral Contraceptive use among female students is very high among those who reported sexual intercourse we recommend that zonal health department, town heath office, Mizan
Tepi University health Science College and Mizan Tepi University HIV coordination should give reproductive health education, risk of unprotected sex.

To prevent unintended pregnancy among sexually active female university students there is a need to improve reproductive health education and provision of services in the existing student health clinic in the campuses.

The current study employed cross sectional descriptive study design that doesn't show cause and effect relationship between independent variables and Emergency Oral Contraceptive. Future researchers should consider prospective study with follow up to identify predictors of Emergency Oral Contraceptive use.

\section{Acknowledgments}

First and for most we would like to express our deepest gratitude and appreciation to our staffs for their unreserved all rounded, support and enriching comment throughout the research and to Mizan Tepi University, college of health science nursing department for giving us a chance to develop this research and for their scientific suggestions through selection of title. We would like to express our heartfelt gratitude to Mizan-Tepi University Students Academic and Alumni Management Directorate for their cooperation and provision of mandatory information. We would like to give a special gratitude to the entire study participants and the data collectors.

\section{Conflict of interest}

All the authors have prepared and checked the data and declare that there is no conflict of interest.

\section{References}

1. Zeiman M. Emergency contraception. 215.

2. WHO. Family planning: A global hand book for health care providers. A WHO family planning corner stone; 2011.

3. Charlotte E. History and Efficacy of emergency contraception: Beyond coca cola. Fam Plann Perspect. 1996;28(2):44-48.

4. Ethiopian Ministry of health. Family Health Department: An assessment of reproductive health needs in Ethiopia. Research on the introduction and transfer of technologies for fertility regulation. WHO, Geneva; 1999.

5. Lemma DA. Emergency contraception in Addis Ababa: practice of service providers. University of South Africa; 2012

6. Szarewski A, Guilleband J. Contraception: A users giude. 2010.

7. Federal ministry of health. National reproductive health strategy in Ethiopia 2006-2015. 2015.

8. Family planning: A global hand book for health care providers. A WHO family planning corner stone; 2011.

9. Altankhuyagiin G, Jane F, James B. Determinants of current contraceptive use and method choice in Mongolia. J Biosoc Sci. 2007;6(39):1-17.

10. http://www.who.int/reproductivehealth/publications/unsafe_abortions/ induced_abortion_2012.pdf

11. Gettmacher Institute and World Health Organization. Facts on induced abortion worldwide, In Brief: Fact Sheet. 2012. 
12. Central Statistical Agency, Ethiopia, ORC Macro. Ethiopia Demographic and Health survey (EDHS) 2011. Addis Ababa, Ethiopia and Calverton, Maryland, USA; 2011.

13. WHO, UNICEF, UNFPA. World bank estimates; Trends on maternal mortality; 1990-2013.

14. Central statistical agency. Ethiopian demographic health survey (EDHS). Calverton, Mary kind USA; 2012.

15. Both R, Samuel F. Keeping silent about emergency contraception in Addis Ababa: A qualitative study among young people, service provider and key stake holders. BMC Womens Health. 2014;14:134.

16. Tilahun D, Assefa T, Belachew T. Predictors of emergency contraception among regular female students at Adama University, Central Ethiopia. Pan Afr Med J. 2011;7:16.

17. Worku A. Knowledge, attitude and practice of emergency contraceptives among female college students in Arba Minch. Ethiop J Heal Dev. 2011;25:176-183.

18. Tajure N. Knowledge, Attitude and practice of emergency contraception among graduating female students of Jimma University, south west Ethiopia. Ethio J health Sci. 2010;20(2):91-97.

19. Akani C, Enyindah C, Babutunde S. Emergency contraception: knowledge and perception of female undergraduates in the niger delta of Nigeria. Ghana Med J. 2008;42(2):68-70.

20. Tilahun D, Assefa T, Belachew T. Predictors of emergency contraception among regular female students at Adama University, Central Ethiopia. Pan Afr Med J. 2011;7:16.

21. Nibabe WT, Mgushine T. Emergency contraception amongst the female college students- Knowledge, attitude \& practice. Afr J prm health care from med. 2014;6(1):538-545.
22. Miruts G, Yeman D, Abera k. Factors associated with emergency contraceptive use among female preparatory school students Adwa town, Northern Ethiopia. IJPSR. 2014;5(10):665-669.

23. Eugene J, Pius Negassa, Nelson F, et al. A survey of knowledge, attitude and practice of emergency contraception among university students in Cameroon. BMC Emerg Med. 2007;7:7.

24. Hoque ME, Ghuman S. Prevalence of Emergency Oral Contraceptive among female university students in Kwazulu-Natal, South Africa. PLoS One. 2012;7(9):e46346.

25. Haile Mariam GT, Tesfaye T, Melese T, et al. Sexual experience and emergency contraceptive use among female university students; A cross sectional study at Wachamo University, Ethiopia. BMC Res Notes. 2015;8:112.

26. Ahmed FA, Moussa KM, Petterson KO, et al. Assessing knowledge, attitude and practice of emergency contraception; A cross sectional study among Ethiopian under graduate female students. BMC Public Health. 2012;12:110.

27. Eugene J, Pius Negassa, Nelson F, et al. A survey of knowledge, attitude and practice of emergency contraception among university students in Cameroon. BMC Emerg Med. 2007;7:7.

28. Hoque ME, Ghuman S. Prevalence of Emergency Oral Contraceptive among female university students in Kwazulu-Natal, South Africa. PLoS One. 2012;7(9):e46346.

29. Tajure N. Knowledge, attitude and practice of Emergency Contraceptive Contraception among graduating female students of Jimma University, southwest Ethiopia. Ethio J Health Sci. 2010;20(2):91-97. 